\title{
Presença de folhas no enraizamento de estacas de amoreira-preta
}

\author{
Presence of leaves on rooting of blackberry
}

\author{
Gerson Kleinick Vignolo ${ }^{\mathrm{I}^{*}}$ Luciano Picolotto $^{\mathrm{II}}$ Michel Aldrighi Gonçalves ${ }^{1}$ \\ Ivan Dos Santos Pereira ${ }^{I I}$ Luis Eduardo Corrêa Antunes"
}

\section{RESUMO}

A propagação da amoreira-preta pode ser feita de forma sexuada ou assexuada, sendo esta última empregada na produção comercial. A utilização de estacas da parte aérea tem como vantagem o aproveitamento de materiais retirados da planta no momento da poda, porém apresenta variabilidade no enraizamento e na brotação. O trabalho teve como objetivo avaliar a influência da presença de folhas no enraizamento de três cultivares de amoreira-preta. $\mathrm{O}$ delineamento experimental utilizado foi em blocos ao acaso, com quatro repetições, em esquema fatorial $3 \times 2$, sendo o fator cultivar representado por três níveis ('Guarani', 'Tupy' e 'Xavante') e o fator presença de folha, por dois níveis (estaca com e sem folha). As avaliações, realizadas 115 dias após a instalação do experimento, foram: porcentagem de estacas sobreviventes, enraizadas e com calo; comprimento da maior raiz e número de raízes por estaca; comprimento das brotações e número de brotações por estaca; massa seca das brotações e das raízes. As cultivares 'Tupy'e 'Xavante' apresentam maior porcentagem de enraizamento do que 'Guarani', além de sistema radicular de melhor qualidade. A presença de folhas proporciona maior porcentagem de enraizamento de estacas lenhosas de amoreira-preta, sendo indispensáveis para a propagação das cultivares 'Guarani', 'Tupy' e 'Xavante' através desse método.

Palavras-chave: Rubus spp, propagação e enraizamento.

\section{ABSTRACT}

The propagation of blackberry can be done in a sexual or asexual form, being used in commercial production. Use of shoot cuttings has the advantage of the use of materials removed from the plant at the time of pruning, but shows variability in rooting and sprouting. The study aimed to evaluate the influence of the presence of leaves on the rooting of three cultivars of blackberry. The experimental design was randomized blocks with four replications, making a 3x2 factorial, with the cultivar factor represented by three levels ('Guarani', 'Tupy' and 'Xavante') and the factor presence of leaf, for two levels (cutting with and without leaves). The assessments done 115 days after the experiment were: percentage of live cuttings, rooted and callus; longest root length and number of roots per cutting, sprouting length and number of sprouting per cutting, dry mass of sprouting and roots. The cultivars 'Tupy' and 'Xavante' have higher rooting percentage than 'Guarani', beyond root system of better quality. The presence of leaves provides more rooting of hardwood cuttings of blackberry, being essential for the propagation of cultivars 'Guarani', 'Tupy' and 'Xavante' through this method.

Key words: Rubus spp, propagation, rooting.

\section{INTRODUÇÃO}

O cultivo de pequenas frutas no Brasil vem crescendo e diversificando-se nos últimos anos, principalmente nos Estados das regiões Sul e Sudeste, que apresentam áreas com clima propício para o cultivo dessas espécies. A expressão inglesa Small Fruits ou pequenas frutas caracteriza culturas nas quais se enquadram a amoreira-preta, a framboeseira, o mirtileiro e o morangueiro. Portanto, a amoreirapreta (Rubus spp.) surge como opção para essa diversificação, pela rusticidade, menor investimento por área e possibilidade de geração de renda (ANTUNES et al., 2010; CAMPAGNOLO \& PIO, 2012a), além das características funcionais que esta fruta apresenta, sendo grande aliada na prevenção de doenças humanas (ANTUNES, 2002).

A propagação vegetativa, ou assexuada, explora a habilidade natural, através da separação de partes vegetativas de um tecido, como as raízes, os brotos e as folhas. Assim, a partir de um simples exemplar (planta) pode-se produzir outra planta

IUniversidade Federal de Pelotas (UFPel), Campus Universitário Capão do Leão s/n, 96900-010, Pelotas, RS, Brasil. E-mail: gerson_vignolo@yahoo.com.br.*Autor para correspondência.

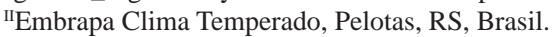


geneticamente idêntica ao progenitor, ou seja, um clone (HARTMANN et al., 2002; TOOGOOD, 2007). Este método de propagação é possível devido a duas propriedades fundamentais das células das plantas, uma é a totipotência, que é a informação genética contida na célula viva da planta, necessária para reconstruir todas as suas partes e funções. A segunda é a desdiferenciação, relacionada com a capacidade previamente desenvolvida das células desdiferenciarem para retornar à condição meristemática e desenvolver um novo ponto de crescimento (HARTMANN et al., 2002).

A propagação assexuada da planta de amoreira-preta se dá por meio de rebentos (brotos), estacas herbáceas e lenhosas, além de estacas de raízes (VILLA et al., 2006; DIAS et al., 2012). A utilização de estacas da parte aérea tem como vantagens o aproveitamento de materiais retirados da planta no momento da poda, porém apresenta variabilidade no enraizamento e na brotação. A utilização de estacas lenhosas na propagação da espécie tem sido utilizada, durante o período de repouso vegetativo, por ocasião da poda, obtendo-se uma grande quantidade de ramos para a produção de estacas, podendo maximizar a utilização do material vegetal que seria descartado (ANTUNES et al., 2000). A presença da folha, por ser fonte de auxina, é um importante fator na promoção do enraizamento de estacas de diversas espécies frutíferas, como mirtilo, framboesa e amora (HARTMANN et al., 2002; OSTERC \& STAMPAR, 2011; UBEDA-TOMÁS et al., 2012).

Assim, objetivou-se, neste trabalho, avaliar a influência da presença de folhas no enraizamento de estacas de três cultivares de amoreira-preta.

\section{MATERIAL E MÉTODOS}

O experimento foi conduzido em casa de vegetação pertencente à Embrapa Clima Temperado, Pelotas-RS, com nebulização intermitente durante todo o experimento, acionada por 10 segundos a cada cinco minutos, sendo a temperatura média e a umidade relativa do ar de $20^{\circ} \mathrm{C}$ e $73 \%$, respectivamente. O município de Pelotas localiza-se a $31^{\circ} 46^{\prime}$ de latitude, com altitude ao redor de $245 \mathrm{~m}$ e temperatura média anual de $17,6^{\circ} \mathrm{C}$.

Foram coletados, em junho de 2011, ramos desenvolvidos neste mesmo ciclo em plantas de amoreira-preta com três anos de idade, das cultivares 'Guarani', 'Tupy' e 'Xavante'. Foram utilizadas estacas lenhosas da parte mediana dos ramos, as quais foram preparadas com aproximadamente dez mm de diâmetro e $10 \mathrm{~cm}$ de comprimento, com um corte horizontal na base e em bisel na extremidade superior. As estacas com folhas permaneceram com apenas uma folha com os folíolos cortados na metade. As estacas foram acondicionadas em bandejas plásticas de dimensões $34 \times 23,5 \times 8,5 \mathrm{~cm}$, tendo como substrato uma mistura de $70 \%$ de vermiculita de textura média com 30\% de serragem de eucalipto.

As avaliações, realizadas 115 dias após a instalação do experimento, foram: porcentagem de estacas sobreviventes, enraizadas e com calo; comprimento da maior raiz $(\mathrm{cm})$ e número de raízes por estaca; comprimento das brotações (cm) e número de brotações por estaca; massa seca (g) das brotações e das raízes. As brotações e raízes retiradas de cada unidade experimental foram acondicionadas em sacos de papel, secas a $65^{\circ} \mathrm{C}$ até atingir massa constante e posteriormente pesadas em balança de precisão.

O delineamento experimental utilizado foi em blocos ao acaso, com quatro repetições e unidade experimental composta por 10 estacas cada, perfazendo um fatorial $3 \times 2$, sendo o fator cultivar representado por três níveis ('Guarani', 'Tupy' e 'Xavante') e o fator presença de folha, por dois níveis (estaca com e sem folha). Os resultados foram submetidos à análise de variância, sendo que, posteriormente, variáveis com diferenças significativas tiveram suas médias comparadas pelo teste de Tukey $(\mathrm{P}=0,05)$.

\section{RESULTADOS E DISCUSSÃO}

Foram observadas diferenças significativas entre as cultivares nas variáveis porcentagem de estacas sobreviventes, estacas com calo, número de raízes e comprimento da maior raiz. A maior quantidade de estacas sobreviventes ocorreu com a cultivar 'Guarani' (100\%), sendo superior à 'Xavante', porém não diferindo de 'Tupy' (Tabela 1). A presença de muitas estacas vivas e não enraizadas na 'Guarani' pode indicar que esta cultivar apresenta formação do sistema radicular mais lenta do que as demais cultivares avaliadas. ANDRADE et al. (2007), avaliando o enraizamento de estacas de amoreira-preta, utilizando diferentes concentrações de AIB, observaram 83\% de sobrevivência de estacas no tratamento sem AIB, valor inferior ao relatado no presente trabalho.

A presença de folhas nas estacas não influenciou a quantidade de estacas sobreviventes. Porém, segundo HARTMANN et al. (2002), a antecipação do enraizamento em estacas com folhas favorece o enraizamento adventício e, consequentemente, a sobrevivência das estacas. 
Tabela 1 - Porcentagem de estacas sobreviventes (ES), com calo (EC), número de raízes e comprimento da maior raiz (CMR) de estacas de amoreira-preta sob influência da presença de folhas em diferentes cultivares. Embrapa Clima Temperado, Pelotas-RS, 2013.

\begin{tabular}{lllcc}
\hline Cultivar & ES (\%) & EC (\%) & N Raízes $^{\circ}$ & CMR (cm) \\
\hline 'Guarani’ & $100,00 \mathrm{a}$ & $77,08 \mathrm{a}$ & $1,31 \mathrm{~b}$ & $2,38 \mathrm{~b}$ \\
'Tupy' & $97,91 \mathrm{ab}$ & $35,41 \mathrm{~b}$ & $2,74 \mathrm{ab}$ & $7,44 \mathrm{a}$ \\
'Xavante’ & $87,05 \mathrm{~b}$ & $33,33 \mathrm{~b}$ & $5,04 \mathrm{a}$ & $5,91 \mathrm{a}$ \\
Folhas & & & $5,06 \mathrm{a}$ & $8,12 \mathrm{a}$ \\
Com & $97,22^{\text {ns }}$ & $37,50 \mathrm{~b}$ & $1,00 \mathrm{~b}$ & $2,36 \mathrm{~b}$ \\
Sem & 93,05 & $59,72 \mathrm{a}$ & 21,72 & 21,40 \\
CV $(\%)$ & 8,80 & 15,77 & \\
\hline
\end{tabular}

* Médias seguidas de mesma letra, minúscula na coluna, não diferem entre si pelo teste Tukey $(\mathrm{P}=0,05)$.

${ }^{\text {ns }}$ Não significativo $(\mathrm{P}>0,05)$.

De acordo com PACHECO \& FRANCO (2008), devido às folhas serem locais de síntese de auxina e carboidratos, espera-se que a presença das folhas favoreça a sobrevivência e a formação de raízes. Além disso, é provável que o enraizamento e a sobrevivência das estacas com folhas estejam relacionados à síntese de compostos fenólicos pela parte aérea. Estudos indicam que certos compostos fenólicos, como é o caso do ácido cafeico, catecol e clorogênico, interagem com as auxinas, induzindo a iniciação das raízes. No entanto, a coleta das estacas foi realizada no período de inverno, quando geralmente os níveis dos promotores de enraizamento estão mais baixos do que no período de desenvolvimento vegetativo. De acordo com MAIA \& BOTELHO (2008), estacas lenhosas de algumas cultivares de amoreira-preta são difíceis de enraizar, por apresentarem maior grau de lignificação e baixos níveis de auxina endógena.

A sobrevivência das estacas não parece depender da fotossíntese realizada pelas folhas, mas sim das reservas que estas formaram antes do período de enraizamento. Para FACHINELLO et al. (2005), tem-se observado que reservas mais abundantes correlacionam-se com maiores percentuais de enraizamento e sobrevivência. Segundo DIAS et al. (2011a), o aumento nos teores de açúcares da parte aérea com relação às raízes pode indicar que a parte aérea atuou como fonte de fotoassimilados e, dentre eles, açúcares solúveis, para promover as brotações.

$\mathrm{Na}$ porcentagem de calo também se destacou a cultivar 'Guarani' (77,08\%), diferindo de 'Tupy’ e 'Xavante’. Comportamento similar foi observado por ANTUNES et al. (2000), já que estacas de 'Guarani' formaram maior quantidade de calo que as cultivares 'Tupy', 'Comanche', 'Cherokee' e seleção 97. Porém, a quantidade de calo é variável com a época do ano e tipo de estaca utilizada, conforme verificado por CAMPAGNOLO \& PIO (2012b). A utilização de estacas com folhas proporcionou uma diminuição significativa da porcentagem de estacas com calo (37,5\%), diferindo significativamente das estacas sem folhas (59,72\%). Possivelmente, as condições que afetam ou favorecem o enraizamento sejam as mesmas que modificam aspectos como a formação de calo e sobrevivência das estacas. No entanto, o presente trabalho demonstra também que a formação de calo depende da cultivar e da presença ou não das folhas no momento do estaqueamento. Segundo HARTMANN et al. (2002), a formação de calo e de raízes são processos independentes para a maioria das plantas. Entretanto, para esses autores, em algumas plantas, a formação de calo pode ser precursora da formação de raízes, porém, na amoreira-preta, isso parece não ocorrer, pois, no presente trabalho, a maioria das estacas que formaram calo, não enraizaram.

Observa-se que a maior quantidade de calo na 'Guarani’ causou o menor número de raízes por estaca entre as cultivares testadas, sendo a 'Xavante' $(5,04)$ a cultivar que apresentou maior número de raízes, porém não diferindo de 'Tupy'. Resultado este que difere do encontrado por CAMPAGNOLO \& PIO (2012b), quando 'Xavante' (6,87) apresentou um menor número de raízes do que ‘Tupy’ $(12,77)$ e 'Guarani' (8,25).

Para a variável comprimento da maior raiz, observou-se superioridade de ambas cultivares sobre 'Guarani' (2,38cm) (Tabela 1). No entanto, ANTUNES et al. (2000) observaram comprimento radicular maior na cultivar 'Guarani' e menor na 'Tupy'. Existe variabilidade de resultados entre diferentes estudos, o que pode ser um indicativo de que outros fatores estejam relacionados ao processo de formação e crescimento das raízes, como, por exemplo, época de coleta, tipo de substrato e ambiente utilizado no enraizamento, entre outros. A presença de folhas nas estacas favoreceu o número e o comprimento das raízes, diferindo das estacas 
sem folhas. As estacas com folhas apresentaram 5,06 raízes e 8,12cm de comprimento da maior raiz, já as estacas sem folhas apresentaram apenas uma raiz por estaca e com apenas 2,36cm de comprimento (Tabela 1). PIO et al. (2004), avaliando a influencia da presença de folhas no enraizamento de estacas de figueira, observaram 6,6, 15,7 e 18 raízes por estaca para os tratamentos sem folha, com uma folha e duas folhas, respectivamente.

A variação no número e comprimento de raízes verificadas em diferentes trabalhos indica que os fatores de enraizamento e crescimento, como, por exemplo, concentração de açúcares e hormônios, também atua e age de forma diferenciada entre as cultivares de amoreira-preta. Segundo ANTUNES et al. (2000), o maior comprimento de raiz pode ter relação com a concentração endógena mais elevada de auxinas, favorável ao maior desenvolvimento do sistema radicular. De acordo com MOUBAYIDIN et al. (2010), o crescimento da raiz ocorre quando, no meristema apical, a divisão celular prevalece sobre a diferenciação, fato que ocorre porque há uma maior concentração de auxinas promovendo a divisão do que citocininas promovendo a diferenciação, indicando que a presença de folhas induziu um balanço favorável às auxinas. DIAS et al. (2011b) verificaram que aplicações endógenas de auxina sintética podem modificar ainda a concentração de açúcares na parte aérea e radicular. A auxina é sintetizada nas gemas apicais e folhas novas, de onde é translocada para a base da planta (FACHINELLO et al., 2005).

A porcentagem de enraizamento foi influenciada pela interação entre a presença de folhas nas estacas e as cultivares utilizadas. A presença de folhas nas estacas estimulou uma maior porcentagem de enraizamento, principalmente para 'Tupy' e 'Xavante', que tiveram incremento de 25,00\% e $20,83 \%$ para $70,83 \%$ e $75,00 \%$, respectivamente (Tabela 2). Porém, ANDRADE et al. (2007), em testes com estacas com um par de folhas, não observaram diferenças na formação das raízes, variando a concentração de AIB utilizada, sugerindo a existência de outros fatores relacionados. Entretanto, podem não ter sido observadas diferenças neste trabalho citado devido a quantidade de auxinas presente nas folhas já terem sido suficientes para a formação das raízes. De acordo com OSTERC \& STAMPAR (2011), as folhas são importantes fontes da síntese de auxinas como o ácido indol-3-acético (AIA). Segundo os mesmos autores, a formação de raízes laterais é regulada antagonicamente pela relação auxinas/citocininas.

A cultivar 'Guarani' foi a que apresentou menor porcentagem de enraizamento entre as
Tabela 2 - Porcentagem de enraizamento e número de brotações de estacas de amoreira-preta sob influência da presença de folhas em diferentes cultivares. Embrapa Clima Temperado, Pelotas-RS, 2013.

\begin{tabular}{lcc}
\hline Cultivar & Presença de folhas & \multicolumn{1}{c}{ Ausência de folhas } \\
& -------------Enraizamento (\%)----------------- \\
\hline 'Guarani’ & $16,66 \mathrm{bA}$ & $4,16 \mathrm{bB}$ \\
'Tupy' & $70,83 \mathrm{aA}$ & $25,00 \mathrm{aB}$ \\
'Xavante' & $75,00 \mathrm{aA}$ & $20,83 \mathrm{aB}$ \\
CV (\%) & & \\
& & 11,72 \\
'Guarani' & $1,49 \mathrm{aA}$ & $0,37 \mathrm{bB}$ \\
'Tupy' & $1,46 \mathrm{aA}$ & $1,00 \mathrm{abA}$ \\
'Xavante' & $1,17 \mathrm{aA}$ & \\
CV (\%) & 21,29 & \\
\hline
\end{tabular}

*Médias seguidas de mesma letra, minúscula na coluna e maiúscula na linha, não diferem entre si pelo teste Tukey $(\mathrm{P}=0,05)$.

cultivares testadas. Segundo FACHINELLO et al. (2005), a potencialidade de uma estaca formar raízes é variável com a espécie e também com a cultivar. VILLA et al. (2003), testando enraizamento de estacas de amoreira-preta cvs. 'Brazos' e 'Guarani', observaram distinto comportamento das duas cultivares, atribuindo como possível causa as diferenças genéticas. O fato da 'Brazos' ter apresentado maior porcentagem de estacas enraizadas sem aplicação de AIB pode indicar um conteúdo endógeno de auxinas apropriado para o processo de formação de raízes. MAIA \& BOTELHO (2008), avaliando o enraizamento de estacas da cultivar 'Xavante', relataram haver necessidade de aplicação de AIB, pois observaram $0 \%$ de enraizamento nas estacas sem utilização de AIB. Possivelmente, esses autores utilizaram estacas sem folhas, pois, de acordo com os dados do presente trabalho, pode-se observar que a porcentagem de enraizamento é bastante superior quando se utiliza estacas com folhas.

Na propagação vegetativa, o sucesso do enraizamento depende de vários fatores, tais como: a quantidade de estacas sobreviventes, a porcentagem de calo, o comprimento das raízes e o número de raízes por estaca. Dentre os fatores que afetam a formação das raízes, pode-se citar a condição fisiológica da planta matriz, tipo de estaca, balanço hormonal, potencial genético de enraizamento, oxidação de compostos fenólicos, entre outros (FACHINELLO et al., 2005). Além dos fatores geralmente relacionados ao enraizamento de estacas, encontra-se a presença de folhas como fator positivo desse evento, corroborando o descrito por DIAS et al. (2012). Na cultivar 'Guarani', a presença de folhas não favoreceu tanto o 
enraizamento como nas cultivares 'Xavante' e 'Tupy', no entanto, foi superior as estacas sem folhas. $\mathrm{O}$ uso de fitorreguladores nesta cultivar foi favorável ao enraizamento, segundo trabalho realizado por VILLA et al. (2003), atingindo 26,9\%. Esses resultados de enraizamento relativamente baixos nas estacas de 'Guarani' podem ser um indicativo de que outros fatores estão envolvidos na formação do sistema radicular dessa cultivar.

No comprimento das brotações, destacouse a cultivar 'Xavante', tanto nas estacas com folhas como nas sem folhas (3,37 e 1,72cm, respectivamente), sendo observado este mesmo comportamento para 'Tupy'. Já na cultivar 'Guarani', a presença de folhas na estaca não influenciou o comprimento das brotações (Tabela 3). Para o número de brotações, o efeito gerado também foi em função da cultivar e da presença de folha. A cultivar 'Tupy' com estacas sem folhas apresentou menor número de brotações do que ‘Guarani’, porém não diferiu de 'Xavante’ (Tabela 2). A formação de novas estruturas na parte aérea da estaca funciona como um forte dreno consumidor das reservas de carboidratos e compostos nitrogenados; portanto, o seu surgimento antes da emissão das raízes na base da estaca pode levar à exaustão dessas reservas, prejudicando o enraizamento ou resultando na morte das estacas (LIMA, et al., 2006).

Para a variável massa seca das brotações e radicular, também houve interação entre as cultivares

Tabela 3 - Comprimento das brotações, massa seca das brotações e massa seca das raízes de estacas de amoreira-preta sob influência da presença de folhas em diferentes cultivares. Embrapa Clima Temperado, Pelotas-RS, 2013.

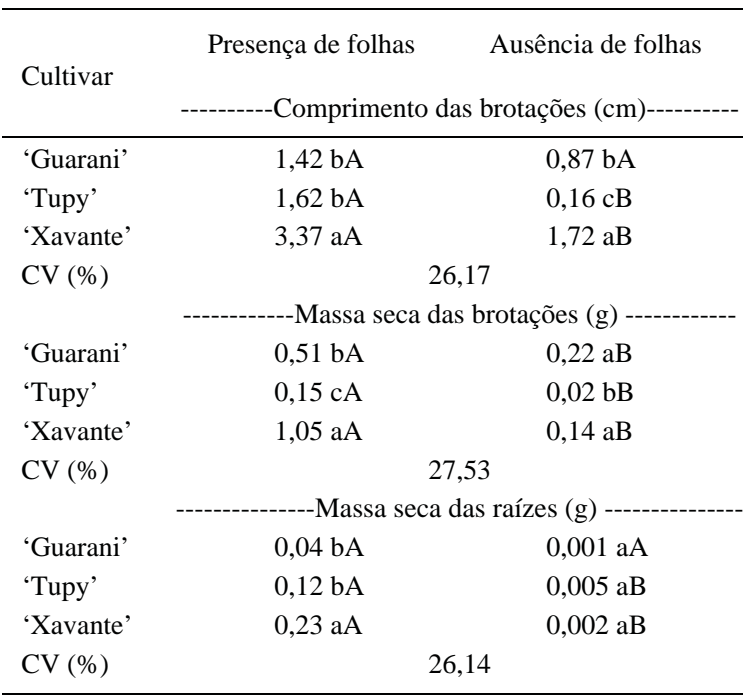

*Médias seguidas de mesma letra, minúscula na coluna e maiúscula na linha, não diferem entre si pelo teste Tukey $(\mathrm{P}=0,05)$. e a presença de folha. Em ambas as cultivares, a presença de folhas proporcionou maior massa seca das brotações do que nas estacas sem folhas. Na cultivar 'Xavante', a presença de folhas na estaca proporcionou $1,05 \mathrm{~g}$, superando os valores observados em estacas de 'Guarani' e 'Tupy'. Quando se utilizaram estacas sem folhas, a massa seca das brotações foi superior nas cultivares 'Guarani’ (0,22g) e 'Xavante' $(0,14 \mathrm{~g})$, diferindo da 'Tupy'. Para a massa seca do sistema radicular, verificou-se maior massa seca da raiz nas estacas com folhas, exceto na cultivar 'Guarani', na qual não se verificaram diferenças significativas (Tabela 3).

\section{CONCLUSÃO}

A presença de folhas proporciona maior porcentagem de enraizamento de estacas lenhosas de amoreira-preta, sendo indispensáveis para a propagação das cultivares 'Guarani', 'Tupy' e 'Xavante' através desse método. As cultivares 'Tupy' e 'Xavante’ apresentam maior porcentagem de enraizamento do que 'Guarani', além de sistema radicular de melhor qualidade.

\section{AGRADECIMENTOS}

Os autores agradecem ao apoio financeiro recebido da Coordenação de Aperfeiçoamento de Pessoal de Nível Superior (CAPES).

\section{REFERÊNCIAS}

ANDRADE, R.A. et al. Propagação da amora-preta por estaquia utilizando ácido indolbutírico. Revista Caatinga, Mossoró, v.20, n.2, p.79-83, 2007.

ANTUNES, L.E.C. et al. Propagação de cultivares de amoreirapreta (Rubus spp) através de estacas lenhosas. Revista Brasileira de Fruticultura, Jaboticabal, v.22, n.2, p.195-199, 2000.

ANTUNES, L.E.C. Amora-preta: nova opção de cultivo no Brasil. Ciência Rural, Santa Maria, v.32, p.151-158, 2002. Disponível em: <http://www.scielo.br/scielo.php?pid=S010384782002000100026\&script=sci_arttext $>$. Acesso em: 20 fev. 2013. Doi: 10.1590/S0103-84782002000100026.

ANTUNES, L.E.C. et al. Fenologia e produção de cultivares de amoreira-preta em sistema agroecológico. Ciência Rural, Santa Maria, v.40, n.9, p.1929-1933, 2010. Disponível em: <http://www. scielo.br/pdf/cr/v40n9/a712cr3622.pdf>. Acesso em: 12 jan. 2013. doi: 10.1590/S0103-84782010000900012.

CAMPAGNOLO, M.A.; PIO, R. Produção de amoreira-preta ‘Tupy’ sob diferentes épocas de poda. Ciência Rural, Santa Maria, v.42, n.2, p.225-231, 2012a. Disponível em: <http://www.scielo. br/scielo.php?pid=S0103-84782012000200007\&script=sci arttext>. Acesso em: 10 fev. 2013. doi: 10.1590/S010384782012005000007.

Ciência Rural, v.44, n.3, mar, 2014. 
CAMPAGNOLO, M.A.; PIO, R. Enraizamento de estacas caulinares e radiculares de cultivares de amoreira-preta coletadas em diferentes épocas, armazenadas a frio e tratadas com AIB. Ciência Rural, Santa Maria, v.42, n.2, p.232-237, 2012b. Disponível em: $<$ http://www.scielo.br/pdf/cr/v42n2/a5812cr5742.pdf>. Acesso em: 06 fev. 2013. doi: 10.1590/S0103-84782012000200008.

DIAS, J.P.T. et al. IBA e carboidratos no enraizamento de brotações procedentes de estacas radiciais de Rubus Spp. Revista Brasileira Fruticultura, Jaboticabal, v.33, n. esp., p.666-671. 2011a. Disponível em: <http://www.scielo.br/scielo.php?pid=S010029452011000500093\&script=sci_arttext $>$. Acesso em: 14 jan. 2013. Doi: 0.1590/S0100-29452011000500093.

DIAS, J.P.T. et al. Enraizamento de estacas de brotações oriundas de estacas radiculares de amoreira-preta. Revista Brasileira de Fruticultura, Jaboticabal, v.33, n. esp., p.649-653, 2011 b. Disponivel em: <http://www.scielo.br/scielo.php?pid=S010029452011000500090\&script=sci_abstract\&tlng=pt $>$. Acesso em: 2 de mar. 2013. Doi: 10.1590/S0100-29452011000500090.

DIAS, J.P.T. et al. Bioestimulante na promoção da brotação em estacas de raiz de amoreira-preta. Revista Brasileira de Fruticultura, Jaboticabal, v.34, n.1, p.1-7, 2012. Disponível em: $<$ http://www.scielo.br/pdf/rbf/v34n1/v34n1a03.pdf>. Acesso em: 18 fev. 2013. doi: 10.1590/S0100-29452012000100003.

FACHINELLO, J.C. et al. Propagação de plantas frutíferas. Brasília, DF: Embrapa informação tecnológica, 2005. 221p.

HARTMANN, H.T. et al. Plant propagation: principles and pratices. 7.ed. New Jersey: Prentice-Hall, 2002. 880p.

LIMA, R. de L.S. de et al. Comprimento de estacas e parte do ramo na formação de mudas de aceroleira. Revista Brasileira de Fruticultura, Jaboticabal, v.28, n.1, p.83-86, 2006. Disponível em: <http://www.scielo.br/pdf/rbf/v28n1/29698.pdf>. Acesso em: 31 jan. 2013

MAIA, A.J.; BOTELHO, R.V. Reguladores vegetais no enraizamento de estacas lenhosas de amoreira-preta cv. Xavante. Semina, Londrina, v.29, n.2, p.323-330, 2008. Disponívelem:<http:// www.uel.br/revistas/uel/index.php/semagrarias/article/view/2823/0>. Acesso em: 22 dez. 2012. Doi: 10.5433/1679-0359.2008v29n2p323.

MOUBAYIDIN, L. et al. The rate of cell differentiation controls the arabidopsis root meristem growth phase. Current Biology, Londres, v.20, n.12, p.1138-1143, 2010.

OSTERC, G.; ŠTAMPAR, F. Differences in endo/exogenous auxin profile in cuttings of different physiological ages. Journal of Plant Physiology, Rockville, v.168, p.2088-2092, 2011.

PACHECO, J.P.; FRANCO, E.T.H. Substratos e estacas com e sem folhas no enraizamento de Luehea divaricata Mart. Ciência Rural, Santa Maria, v.38, n.7, p.1900-1906, 2008. Disponível em: $<$ http://www.scielo.br/pdf/cr/v38n7/a15v38n7.pdf>. Acesso em: 06 fev. 2013. doi: 10.1590/S0103-84782008000700015.

PIO, R. Presença de folhas e gema apical no enraizamento de estacas herbáceas de figueira oriundas de desbrota. Revista Brasileira de Agrociência, Pelotas, v.10, n.1, p.51-54, 2004. Disponível em: <http://www.ufpel.edu.br/faem/agrociencia/ v10n1/artigo06.htm>. Acesso em: 25 mar. 2013.

TOOGOOD, A. Enciclopédia de la propagación de plantas. Barcelona: Blume, 2007. 320p.

UBEDA-TOMÁS, S. et al. Hormonal regulation of root growth: integrating local activities into global behavior. Trends in Plant Science, Londres, v.17, n.6, p.326-331, 2012.

VILLA, F. et al. Propagação de amoreira-preta utilizandose estacas lenhosas. Ciência e Agrotecnologia, Lavras, v.27, n.4, p.829-834, 2003. Disponível em: <http://www.scielo. br/scielo.php?pid=S1413-70542003000400013\&script $=$ sci arttext>. Acesso em: 26 jan. 2013. Doi: 10.1590/S141370542003000400013

VILLA, F. et al. Multiplicação in vitro de amoreira-preta

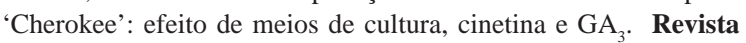
Ceres, Viçosa, v.1, n.1, p.357-362, 2006. 